\title{
ENTREVISTA A ENRIQUE DUSSEL POR JULIANA MERÇON
}

El pensamiento de Enrique Dussel constituye un marco significativo en la historia de la filosofía latinoamericana. Crítico de la postura eurocéntrica adoptada en nuestros países y proponente de una historia filosófica que parte de la geopolítica, Dussel ha capturado la atención de muchos que se lanzan al desafío de un pensar no colonizado. Nacido en Mendoza, Argentina, se refugió en 1975 como exilado político en México, donde ha vivido desde entonces, consolidando su carrera filosófica.

La presente entrevista ocurrió en una fría mañana michoacana, en noviembre de 2009. El texto que sigue es una transcripción de aquel diálogo oral y trasluce, a través de su estilo coloquial, el carácter espontáneo e informal del encuentro.

Propongo que exploremos algunas relaciones entre tres grandes temas: la filosofía, la política y la educación. Le pregunto inicialmente sobre los desafíos que enfrenta la filosofía latinoamericana para afirmarse de forma creadora y no instaurar un campo meramente reactivo en su crítica al eurocentrismo.

La filosofía siempre asume su propio momento. La gran filosofía latina del siglo XIII fue la gran filosofía árabe de Bagdad y ésta, a su vez, fue la gran filosofía persa, bizantina y griega. Siempre la filosofía toma de los anteriores y al principio reacciona. En la Summa contra gentiles Tomás de Aquino ataca a los árabes pero, al mismo tiempo, está construyendo una filosofía propia.

La creación es un momento posterior a la crítica. El hijo se rebela contra el padre con el lenguaje del padre. Así va construyendo su propia lengua. La filosofía árabe incluida en la llamada Edad Media también se construyó. El pensamiento árabe tiene un lenguaje filosófico propio. Inventaron otras palabras porque tuvieron que pensarlas. Y lo mismo nosotros. Hay crítica reactiva, pero también constructiva. Siempre hubo filosofía creativa. 
Sarmiento, al que yo critico muy duro, en su libro Civilización y barbarie plantea una tesis que ningún europeo podía pensar porque él estaba en un país colonial. iBárbaro! A partir de una mirada de los europeos como civilizados piensa qué hacer con la barbarie en Argentina y toma el ejemplo de un caudillo. Esta decisión lo lleva a negar a los propios. Eso solamente lo puede hacer alguien que está ahí. Es un poco lo que les pasó a los extremistas en Brasil que tomaron el positivismo europeo y rechazaron todo lo propio. Eso también es una creación porque hay un proceso de modernización. Esto también es una creación. Tendremos que ver hasta qué punto siempre hubo filosofía creadora. Desde el siglo XVI, hubo ya filosofía creadora en América Latina. Lo que no ha habido ha sido una buena historia de la filosofía creadora. En la actualidad, hay que incluir los grandes temas y elaborarlos bajo esta perspectiva.

¿Cómo vería usted la problemática de la enseñanza de la historia de la filosofía con programas que en muchos casos no incluyen, por ejemplo, el pensamiento latinoamericano, africano u oriental?

Esto ocurre porque todavía predomina una definición eurocéntrica de la filosofía, y en esa definición muchos, como los orientales por ejemplo, no son considerados filósofos. Pero, si entendemos la filosofía de otra manera, sí son filósofos. ¿Qué significa ser filósofo? Si tomamos la palabra, etimológicamente, el filósofo es el que ama la sabiduría. Y todos los pueblos tienen sabiduría. Todas las culturas grandes, pero también las más pequeñas -como los tupinambás de Brasil que estudia Lévi-Strauss. Lévi-Strauss pasa diez años en Brasil (ningún brasileño se pasa diez años con los tupinambás) e inventa el estructuralismo en ese país. Ningún brasileño había pensado nunca en los tupinambás porque eran considerados unos pobres indios desgraciados. Lévi-Strauss pudo escribir libros enteros sobre los mitos tupinambás en Brasil y mostrar su racionalidad.

El ser humano desde siempre, desde el homo sapiens, pero yo creo que también desde el neanderthal, ya se preguntaba por qué hay fuego, por qué hay 
truenos, por qué existe el universo. Se preguntaba por las cosas y por el significado del ser humano.

El ser humano tuvo preguntas que respondió míticamente - mitopoiesis. Los mitos son narrativas racionales. Ra-cio-na-les porque dan razones, las que fueren, pero dan razones y todos las aceptan. Se interpreta el mundo desde sus mitos originales. Tenemos mitos hasta hoy: el mito del progreso, por ejemplo. Es un mito que está debajo de la ciencia y que no sólo no es racional sino que, además, es falso! (Risas). Eso es lo que hace Franz Hinkelammert en la Hacia una crítica de la razón mítica. Si el mito es una narrativa racional en base a símbolos, lo que podríamos llamar amor a la sabiduría consiste en empezar pasar del símbolo al concepto unívoco. Yo veo que si Quetzalcoatl es divino, Coatl, el otro concreto no es sólo una formulación simbólica, ya es un concepto. Los aztecas ya estaban pasando del símbolo al concepto unívoco, ya estaban haciendo filosofía. Hay que definir la filosofía, no como el pasaje del mito al logos, sino el pasaje del logos del mito a otro tipo de logos y sin negar el mito porque, de hecho, sigue existiendo hasta hoy. Si empezamos a definir la filosofía de otra manera, vamos a ver que hay filosofía en Egipto, hay filosofía en la Mesopotamia, hay en China, en todas partes. Los aztecas y los incas también tienen su filosofía. Yo digo que hay racionalización en lo simbólico. Ahora, la filosofía griega es de las pocas filosofías realmente muy especiales - y la moderna aún más especial - pero eso no implica que sea la que me da la definición con la que voy a medir las otras. Entiendo la filosofía desde una definición más universal.

Por todo eso al libro que voy a publicar, ahora en un mes y medio, le hemos puesto el título El pensamiento filosófico. Como para decir, bueno, lo filosófico estricto sensu sería algo ya dominado por una lógica. Pero inclusive pensando así, yo creo que los aztecas, los mayas y los incas ya tenían una filosofía al nivel de los presocráticos, de Parménides ciertamente. Y si Parménides es tomado como un filósofo, los aztecas tienen en Nezahualcoyotl también un místico que habla del universo y de la verdad.

Leemos la prehistoria, pero después tenemos el choque de Europa, de una escolástica que no era medieval, una escolástica moderna. Yo me pregunté por 
qué hay preguntas que nadie se hace. Todos dicen escolástica medieval. iEscucha! Todo el mundo piensa escolástica = medieval. Nadie se pregunta si la escolástica del siglo XVI es moderna. No conozco a nadie que lo haya preguntado. Ginés de Sepúlveda dice: "estos son bárbaros porque no tienen propiedad privada ni tienen herencia”. Esa es una afirmación muy burguesa. Medina del Campo (que viene de "mediná", ciudad en árabe), como otras ciudades de España, era una ciudad mercantil conectada con Bagdad y con Afganistán por el mundo árabe. Era una ciudad comercial. Este tipo de ciudades no eran medievales. En España casi no había feudalismo. El feudalismo llegó muy tarde porque el mundo árabe no era feudal. En Medina del Campo hubo una revolución burguesa en 1519. Los comuneros se levantaron contra el rey defendiendo el fuero que eran los burgueses y el rey los hizo pedazos.

El filósofo jesuita Francisco Suárez es el padre de toda la modernidad. Suárez tenía incluido entre los suyos a gente que había estado en Brasil, en México, en Angola, en Mozambique, en Japón y en China. Tenía alumnos que habían estado en todo el mundo. Nadie en París, Berlín o Londres tenía alumnos que habían estado en todo el mundo. Suárez plantea el yo de una manera cartesiana. Descartes está todo en Suárez. Él escribe las meditaciones. Las Disputaciones Metafísicas, es el primer libro que no sólo realiza un comentario a Aristóteles sino que organiza por primera vez lo que vamos a llamar la metafísica: el ser infinito y el ser finito. Spinoza habla del ser infinito. Ha leído Suárez y en forma muy precisa. Y Descartes cuando teoriza sobre el 'yo' hace una demostración de la existencia de Dios y a lo que llega es al infinito: Suárez. Digo entonces, que esa filosofía nuestra no es otra que las filosofías árabe y judía de la edad media que se conectan a la ilustración, desde Averroes, Maimónides, ... Por lo tanto, habría que tener otra idea de la filosofía. Los chinos no sólo tienen filosofía sino que es de gran nivel. Yo estoy leyendo ahora Lao Tse. Se ha descubierto hace veinte años una colección de textos del Tao. Tenemos tres textos: el más grande, el más pequeño y uno más central. Bueno, uno se pone a pensar: el Tao es un camino, pero es el absoluto. Y se da cuenta que hay allí una gran filosofía. 
Platón y Aristóteles son considerados filósofos porque desarrollan un logos. Aristóteles se vale de la lógica, pero Platón es mucho más dialógico, utiliza una tecnología mucho más china cuando se pregunta y responde. En sus textos las cosas no están tan claras, se vale de mitos - como el de la caverna. Si uno aprende el método filosófico de Platón es mucho más parecido, a veces, al chino que al de Aristóteles. El método socrático es un método muy abierto.

¿Usted vería retos en una política filosófica - y en una filosofía política - que se basa en la identidad? ¿Alguna dificultad en la afirmación de la identidad como noción política?

La noción de identidad es inevitable. Porque hay una comunidad humana en donde cada singular es una corporalidad viviente que ocupa el espacio y el tiempo, y tiene un cerebro en el tiempo y en el espacio. La reflexión es en el espacio y el tiempo y supone una historia, una geografía y una geopolítica. Mi libro Filosofía y liberación empieza por geopolítica y filosofía.

La dificultad está en el asunto de poder comunicar las distintas identidades. Yo no estoy en contra de la universalidad. Creo que los seres humanos de cualquier parte al fin descubren aspectos que son válidos para todos, para toda la humanidad. No estoy en contra de la universalidad. Lo que pasa es que esa universalidad es accedida desde la particularidad y desarrollada desde la particularidad y después pasa a otros. Hay una evolución en ciertos lugares históricos que desarrollan -hasta por condiciones económicas- una técnica de escritura. La escritura es fundamental. La escritura que surge al 3000 a.C. entre Babilonia y Egipto les permite ir memorizando y eso es algo fantástico.

Pensemos en la particularidad de las experiencias políticas desde el zapatismo, la revolución bolivariana y los procesos que están siendo gestados con Evo Morales en Bolivia. Tomando estos tres puntos particulares en la geografía Latinoamericana ¿Cuáles serían algunas de sus potencialidades políticas? 
El pensamiento moderno, al mismo tiempo que realiza enormes avances, tiene limitaciones muy fundamentales cuyos aspectos negativos son los que nos está mostrando la peligrosidad de la hipótesis de Bacon y de la ciencia moderna. La ciencia moderna ha entrado a comprender la realidad de una manera más profunda, y hay que intervenir en ella, pero de pronto está surgiendo el problema de los efectos negativos y esto no estaba en el paquete, no estaba en las hipótesis. Si el sistema no es perfecto tiene efectos negativos y alguien los sufre, eso es lo que pasa con el capitalismo. Estamos viendo que hay un límite absoluto, que es la extinción de la especie humana. Eso nos pone en alerta total porque ahora sí podemos destruir toda la vida de nuestra especie. En el paleolítico alguien agarraba un fémur y les pegaba a los cinco que tenía alrededor pero no podía matar a todos. En cambio hoy, aprieto un botón y explota la tierra. Hemos llegado a un extremo. Ahora sí ya tenemos que tomar responsabilidades por lo que estamos haciendo. Tenemos que aprender de otras experiencias que son más humildes. Nos interesa empezar a pensar otros modos de vida. Por eso surge ahora el aprendizaje de otras culturas.

Con respecto a lo nuestro, en Bolivia los indígenas tienen una experiencia política, pero a un nivel aldeano que no es nacional, que no es un Estado. Ahora tienen el desafío de armar todo el Estado de forma distinta a aquél que se constituyó en base a la invasión. En la conquista se destruyó el imperio inca, que quedó reducido a pequeñas aldeas en las que siguieron viviendo desde un recuerdo mínimo porque perdieron los grandes sabios. Hoy conocen el $5 \%$ de lo que era la sabiduría de los incas. Han perdido el 95\%. Sin embargo, ese pequeño resto que queda lo han seguido cultivando y ahí hay cosas de las cuales nosotros podemos aprender. Una de las cosas que podemos aprender es la vida comunal.

El hombre moderno individual se ha desconectado. El yo se ha querido no intersubjetivo y eso hasta le ha producido enfermedad psíquica y política que atentan contra la vida. Hay que aprender muchas cosas y hay que empezar de nuevo. Los indígenas de Bolivia están ahora con originalidad expresando esto, haciéndolo institucional e intentando hacer un sistema legal y coherente. Tenemos cosas que aprender hasta en el sistema jurídico. 
Nosotros tomamos a una persona como responsable de su acto y entonces la castigamos por el efecto de ese acto. Mató a otro y lo meto preso. El indígena dice "éste mató a aquél" y no sólo se pregunta por qué lo mató sino que la comunidad es responsable por el asesino. Yo soy responsable por el asesino, yo tengo responsabilidad sobre este hombre que mató. Hay que ver por qué ese asesino es víctima de una sociedad de la que yo soy parte. El castigo no va a ser individual, el castigo es para la sociedad que tendrá que reintegrarlo. Entonces, en vez de meter el asesino preso - porque con el asesino preso y con el muerto que desapareció, dos familias se quedan sin comer - lo que hacen los indígenas es agarrar al asesino y hacerlo trabajar el campo del muerto primero, y luego el suyo. Las dos familias ganan. Él públicamente tiene que cumplir su castigo: ir a trabajar el campo. Y la gente dice: "ese es un asesino, pero está pagando su culpa". Después de un tiempo va a ser reintegrado por la sociedad y, en ese acto, la misma sociedad va a decir: "también nosotros pagamos el castigo de haberlo hecho asesino a él". No se necesita la prisión, no se necesita vigilar y castigar, como dice Foucault. Es una sociedad más justa, más inteligente jurídicamente que el derecho romano. Entre los indígenas no hay homo sacer, como dice Agamben. Nosotros podemos pensar y decir iucha! acá hay ideas muy interesantes que pueden ayudarnos a redefinir todo el sistema jurídico desde un concepto distinto de castigo y de culpabilidad.

Esto lo discutía con el ministro de justicia de Bolivia, con 500 jueces y con la gente, claro. Yo le daba muy duro porque ellos siguen siendo eurocéntricos. Les daba, entonces, ánimo volver a repensar todo y darse cuenta de que están en un laboratorio maravilloso al que hay que saber sacarle provecho. Yo, como intelectual, pude animar a la gente, de hecho me di cuenta el golpe que les cogió. El subministro de justicia me dijo: "usted no se imagina lo que ha hecho aquî". Yo justifiqué en el consenso crítico de los oprimidos la nueva legitimidad y legalidad que hacen parte de su constitución. Les hices pensar eso - no tenían estructuras teóricas para pensarlo. Decían: "No tenemos estructuras para pensar. Tenemos que oponernos a todo lo que estudiamos en la facultad de derecho". Años y años 
$y$, de pronto, me encuentro en un lugar donde es justo lo que hay que decir y se hace historia.

Aún podemos reconstruir modelos de comunidad. Al psicoanálisis tenemos que lanzarlo como psicoanálisis comunitario. Tenemos que modificar los mitos, el supuesto psicológico y tendríamos que reincorporar el concepto de comunidad a todos los niveles de la vida cotidiana, de la vida psíquica y de las instituciones.

Hace poco usted mencionaba a Foucault... me pregunto si el modelo de comunidad que hemos concretado en la educación no sigue reproduciendo la estrecha relación entre teología y política... ¿No sería el poder pastoral lo que predomina en la educación? ¿No sería la comunidad educativa un gran rebaño...?

Sí, claro, pastoral, pero usted tiene en Brasil a Paulo Freire. Paulo Freire vio todo esto. Yo digo que es el cursor del siglo XX. Hay que ver la diferencia entre el Emilio (de Rousseau) y la propuesta de Paulo. El Emilio es un niño huérfano. Paulo Freire parte de un adulto miembro de una comunidad que tiene cultura. El Emilio hace un contrato con el maestro y el maestro le dice: "eres libre en todo, pero me tienes que obedecer" - un ego magistral dominador. En cambio, para Paulo Freire, la comunidad es la que lentamente se transforma en el maestro de sí mismo. El método es político, por eso los pedagogos no lo aceptan, dicen: "Paulo Freire es un político". iClaro que es un político! porque hace tomar conciencia política de su condición a un oprimido, condición que le impide ser educado. Lo primero que se le impide es reconocer la propia cultura como digna. En Paulo Freire usted tiene al genio que se adelantó a sus propias explicaciones, dado que usó la comunidad dialógica adulta que afirma su cultura y que critica la dominación y él mismo no puede explicarlo. Digo, ahí tiene usted al genio.

En mi Pedagógica de la Liberación lo que digo es: voy a fundamentar filosóficamente el método de Paulo Freire y lo hago a partir de algunos indicios que él da. Él ha leído un poco a Sartre, ha leído a los existencialistas, tiene cierta visión. Yo profundizo en lo que está implícito en su pensamiento y empiezo a trabajar en su línea. 
Paradójicamente, en las facultades de pedagogía prefieren tomar al suizoginebrino - ¿cómo se llama? - Jean Piaget... y no se dan cuenta que Paulo Freire le lleva un siglo a Piaget. Es interesante, Piaget experimentó su método en sus propios hijos. Y en Ginebra, en la misma ciudad, Paulo Freire trabajó con hijos de obreros portugueses. El hijo de un profesor y el hijo de un obrero y métodos distintos. Paulo Freire está más allá de la modernidad y nos ofrece un ejemplo de comunidad.

Respecto de la relación teología y educación... El tema que Walter Benjamin ha relanzado dentro de la tradición judía contemporánea es muy importante: el tema del Mesías. El Mesías es el maestro y el que inaugura una etapa de creación. Como esta etapa es tan novedosa hay que formar a las nuevas generaciones. La tarea pedagógica es, por lo tanto, fundamental. No se trata de educar a las nuevas generaciones para que cambien las cosas. No, no. El cambio está siendo. Es necesario entenderlo, profundizarlo y formar a gente para que lo continúe.

Una educación donde se vea al discípulo como creador, como actor, que sepa expresarse, que sepa discutir, que sepa acordar, que sea tolerante y humilde para aceptar algo que es más importante y que, al mismo tiempo, sepa defender su pensamiento.

Ahora, en cuanto a la teología, estoy leyendo el libro de Agamben que se llama El reino y la gloria. Él hace lo que dijo Marx: hace la crítica a la teología y para hacer la crítica a la política habla de la teología política presente en la secularización. Agamben toma los autores que trabaja y hace algo fenomenal. Sumar al mesianismo el materialismo histórico implica que el mesianismo gestiona la historia desde los oprimidos, desde los esclavos. Agamben no lo ve. Gestionar la historia desde los oprimidos es la misión de esos mesiánicos que se llaman cristianos. Los únicos que la han repensado -no son los europeos ni los norteamericanos- son los pensadores de la teología de la liberación latinoamericana. Esta perspectiva es la única que entiende que la gestión de Dios se hace desde los oprimidos, desde las víctimas. Allí hay mesianismo más materialismo histórico. 
¿Cómo vería el rol de la educación en la discusión sobre la descolonización y la poscolonización?

Por una parte planteo la filosofía de la Liberación; Aníbal Quijano, por otra parte, planteó la colonización del poder en el racismo. Con un grupo de jóvenes (un grupo posmoderno, pero que después dejan el posmodernismo) Santiago Castro Gómez, Walter Mignolo, Nelson Maldonado y gente que está en Estados Unidos coincidimos en el tema de la descolonización. Al fin, la descolonización es tomar conciencia de que todavía seguimos colonizados. Cuando muestro esta historia es para descolonizarnos. Sin embargo, la descolonización es sólo un momento negativo. Debe haber también un momento positivo, la construcción creadora, que es algo así como la liberación.

Hay que prestar atención porque la descolonización es lo que ahora nos aprieta y nos exige terminar de realizarla. La descolonización no la hemos terminado y supone la experiencia política de un pueblo descolonizado. Vuelvo a insistir: habrá que pasar después al ejemplo creativo, a la afirmación creativa. Eso es lo que estoy haciendo. En el esquema de lo nuevo, estoy pensando que tengo que escribir un libro sobre los grandes mitos: el mito de Edipo y de Abraham, el prometeico y el mesiánico y mostrar la diferencia de estructura de los dos, cómo uno justifica el sistema y el otro el proceso. Mostrar, a conciencia plena, que los mitos siguen vigentes y que hay que saber hacer la crítica de ellos. Es lo que Franz Hinkelammert propone en Hacia una crítica de la razón mítica - muy interesante su libro. Después habría que incorporar los grandes mitos también de las culturas amerindias. También tendríamos que ver cómo funcionan justamente las culturas semitas en la historia universal. Entre la Mesopotamia y Egipto, que fueron las dos grandes primeras culturas, está un desierto y Palestina. En ese mundo surge un pensamiento crítico antiquísimo, de significación mundial y eso hay que pensarlo. Me pueden criticar entonces y decir "usted no es eurocéntrico pero es semitocéntrico". Cada cultura puede encontrar también estos elementos y desarrollarlos. No importa quién históricamente fue el primero en descubrirlo. Fue 
por una situación geopolítica que empezamos a hablar de la universalidad y la particularidad.

\section{Algunas obras de Enrique Dussel}

América Latina dependencia y liberación. Antología de ensayos antropológicos y teológicos desde la proposición de un pensar latinoamericano, 1973.

Filosofía de la liberación, 1977.

La pedagógica latinoamericana, 1980.

Ética comunitaria, 1986.

Historia de la filosofía y filosofía de la liberación, 1994.

Ética de la liberación en la edad de la globalización y la exclusión, 1998.

Hacia una filosofía política crítica, 2001.

Ética del discurso y ética de la liberación (con Karl-Otto Apel), 2005.

Filosofía de la cultura y la liberación, 2006.

Política de la liberación. Historia mundial y crítica, 2007.

Historia del Pensamiento Filosófico Latinoamericano, del Caribe y "Latino" (13002000), 2009. 